\title{
A survey on the impact of the training period on empowering management team: A case study Saipa Group
}

\author{
Hasan Darvish $^{\mathrm{a}^{*}}$, Amir Hossein Amir Khani ${ }^{\mathrm{a}}$, Mahsa Assarhab and Hossein Sotodeh Arani ${ }^{\mathrm{c}}$
}

${ }^{a}$ Department of Economy, Management And Accounting, Payam Noor University, Tehran, Iran

${ }^{b}$ Department of Public Administration, Payame Noor University, PO BOX: 19395 - 4697, Tehran, Iran

${ }^{c}$ Management Group, Payame Noor University PO BOX: 19395 - 4697, Tehran, Iran

\section{CHRON I C LE A B T R A C T}

Article history:

Received January 14, 2013

Received in revised format

24 April 2013

Accepted 25 April 2013

Available online

April 292013

Keywords:

Empowering

Saipa Group

Training program

\begin{abstract}
Having reliable and skilled employees are essential component of any organization. Employees are considered as intangible assets for most organizations and they are the primary source of making value added decisions. On the other hand, a learning organization is capable of making continuous improvement and survives in today's competitive environment. The proposed study of this paper considers whether training programs could empower employees who were working as managers for Saipa Group Company, a well-known automaker in Iran. The study concentrates on those employees who participated in master program in one of educational organizations in city of Tehran, Iran. 178 managers attended this program representing approximately $70 \%$ of total managers. The results of our survey have indicated that while training programs have created meaningful sense and help them have a better sense of efficacy it has not created any feeling of competence or building feeling of self-organization. The survey also concluded that training programs could increase the level of meaningful sense and the feeling of competence. In addition, the results indicate that training programs could increase employees' self-organization as well as efficacy characteristics.
\end{abstract}

\section{Introduction}

Training plays an important role on empowering employees and it could help them contribute more on any organization. However, it may not be able to increase the necessary skills needed to build a value added business unit. Some studies suggest that training programs could increase cooperation among employees while they attend such programs (Conger \& Kanungo, 1988). Page and Czuba (1999), for instance, presented a comprehensive definition on empowerment as a multi-dimensional social process, which could help us gain control on our lives. Honold (1997) covered a review of the literature on employee empowerment during the past century.

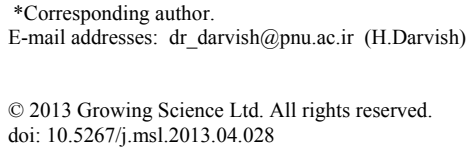


Quinn and Spreitzer (1997), for instance, aurgued that implementation of empowerment programs for employees often proves to be a tedious task in large organizations. They presented seven critical questions about possible challenges of implementing employee empowerment. Shelton (2002) investigated the relationship between employee trust in the supervisor and a sense of employee empowerment. He made some modification on some indices for empowerment, procedural justice, and interactional justice for his survey and reported that there was a link between employee trust in supervisors and employee perceptions of empowerment. In addition he reported that employee trust in the supervisor had a strong relationship with a sense of employee empowerment. The results indicated that as an organization attempts to implement employee empowerment it would need to pay more attention to the level of employee trust in the supervisor as a mean to improve implementation success.

Eylon (1998) performed a comprehensive review on understanding the structure of empowerment. Johnston (2000) investigated some delegation and organizational structure in small businesses influences of manager's attachment patterns. Matthews et al. (2003) developed a scale to measure three environmental factors of dynamic structural framework, control of workplace decisions, and fluidity in information sharing associated with employee's perception of empowerment. They suggested environmental changes they can use to improve perceptions of empowerment on the part of employees. Hon (2011) applied the theory of self-concordance and adopted the multi-level analysis approach to study the mediating impact of employee self-concordance, a core component of intrinsic motivation, on the relationship between social-contextual factors and creativity based on hotel industry data obtained from Mainland China. They reported that organization environment plays essential role in forecasting employee creativity.

According to Yuan and Lee (2011), leadership plays essential role on maximizing efficiency and access to organizational objectives. They conducted a survey to explore a theoretical model, which linked to different leadership types, organization cultures, employees and performance. They reported significant differences between the employees' perceived leadership types, organization cultures, leadership performance and firm's background. Karatepe (2013) investigated whether work engagement could function as a mediator of the impacts of high-performance work practices (HPWPs) on job performance and extra-role customer service. These relationships were evaluated using structural equation modeling based on the data gathered from full-time frontline hotel employees and their managers in the Poiana Brasov region in Romania. They reported that work engagement could act as a full mediator of the impacts of HPWPs on job performance and extra-role customer service.

Amir Khani et al. (2013) presented an empirical investigation to study the effects of spiritual on empowering employees of Payame Noor university in city of Tehran, Iran. They implemented two benchmark questionnaires to study the hypotheses of this survey. There were seven sub-hypotheses associated with this study including the relationship between empowering employees from one side and vision, friendship, faith to work, being meaningful, organizational membership, organizational commitment and performance feedback. The results of implementation of structural equation modeling confirmed all sub-hypotheses except commitment.

Abtahi and Saadi (2012) studied the effect of structural factors on empowering employee in banking sector. They selected 1859 employees who worked in 11 various areas of an Iranian bank called Tejarat. The proposed study of the paper discussed the finding associated with two departments of engineering and administration. Using a standard questionnaire, they gathered the necessary data and the results were validated using Cronbach Alpha and factor analysis. They implemented five different regression techniques to analyze the data and independent variables include complexity, formality and concentration. In addition, the dependent variables included self-effectiveness, self-organization, meaningful, self-acceptance and trust. The results indicated there was no correlation among structural components in engineering and administration areas. 


\section{The proposed study}

The proposed study of this paper considers whether there is a meaningful difference between the employees who were enrolled in training programs and those who were not. The main hypothesis of this survey is as follows,

Main hypothesis: There is a meaningful difference between the employees who were enrolled in training programs and those who were not.

In order to test the main hypothesis of this survey, we develop eight sub-hypothesis as follows,

1. Trained employees have different meaningful sense compared with untrained employees.

2. Trained employees have different feelings of competence compared with untrained employees.

3. Trained employees have different feeling of self-organization compared with untrained employees.

4. Trained employees have different sense of efficacy compared with untrained employees.

5. Trained employees have higher level of meaningful sense compared with untrained employees.

6. Trained employees have higher level of feelings of competence compared with untrained employees.

7. Trained employees have higher level of feeling of self-organization compared with untrained employees.

8. Trained employees have higher level of sense of efficacy compared with untrained employees.

Fig. 1 demonstrates the proposed study of this paper.

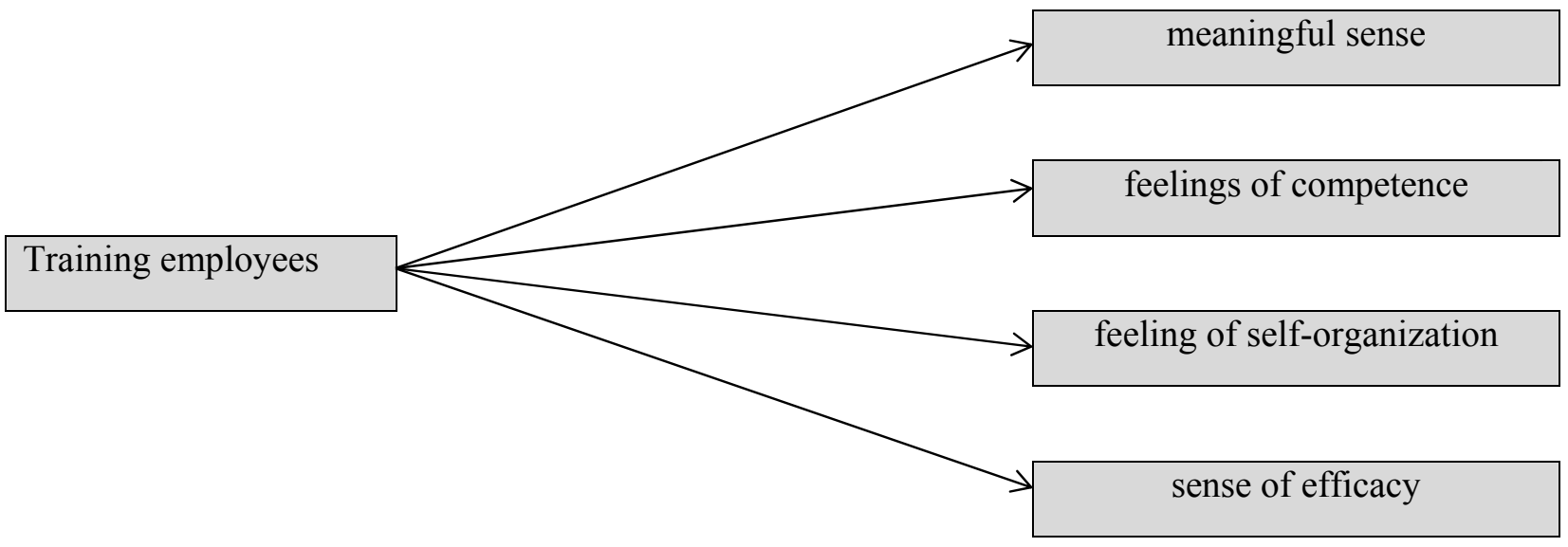

Fig. 1. The proposed study

The proposed study of this paper has performed among employees who worked for Saipa Group Company, a well-known automaker in Iran. The study concentrates on those employees who participated in master program in one of educational organizations in city of Tehran, Iran. There were 
178 managers who attended this program and 80 employees who were not. We use the following formula to calculate the minimum number of sample size,

$$
n=\frac{N \times z_{\alpha / 2}^{2} \times p \times q}{\varepsilon^{2} \times(N-1)+z_{\alpha / 2}^{2} \times p \times q},
$$

where $N$ is the population size, $p=1-q$ represents the yes/no categories, $z_{\alpha / 2}$ is CDF of normal distribution and finally $\varepsilon$ is the error term. Since we have $p=0.5, z_{\alpha / 2}=1.96$ and $N=258$, the number of sample size is calculated as $n=80$. The proposed study of this paper uses Spreitzer's questionnaire (Spreitzer, 1996) which contains 16 questions for empowering employees. In order to verify the quality of the questionnaire, we have chosen a sample of 30 employee and calculated Cronbach alpha as 0.92 , which confirms the overal quality of the questionnaire. In addition, Cronbach alpha has been calculated as 0.896 for the entire questionnaire, which validates the overal survey. Finally, Cronbach alpha was also measured for each four dimension of the questionnaire and the results for meaningful sense, feelings of competence, feeling of self-organization and sense of efficacy were $0.772,0.632$, 0.662 and 0.762 , respectively.

\section{The results}

We first examine the first four hypotheses of our survey using Mann-Whitney test. Table 1 demonstrates the results of our survey.

\section{Table 1}

The results of testing the main hypothesis and first four sub-hypotheses using Mann-Whitney test

\begin{tabular}{llccll}
\hline Hypothsis & The effects of trainig on & Mann-Whitney & $Z$ & Sig. & Result \\
\hline Main & Empowering employees & 1233 & -1.954 & 0.051 & Reject \\
Sub-hypothsis 1 & Creating meaningful sense & 1217 & -2.067 & 0.039 & Confirmed \\
Sub-hypothsis 2 & Building feelings of competence & 1451 & -0.689 & 0.491 & Reject \\
Sub-hypothsis 3 & Establishing feeling of self-organization & 1453 & -0.677 & 0.498 & Reject \\
Sub-hypothsis 4 & Sharing sense of efficacy & 969 & -3.542 & 0.000 & Confirmed \\
\hline
\end{tabular}

The results of the implementation of Mann-Whitney test indicate that training programs were not be able to empower employees. In addition, the results of our survey indicate that while training programs could create meaningful sense and help them have a better sense of efficacy but it does not create feeling of competence or establish feeling of self-organization.

Table 2

The results of testing the second four hypotheses using binary test

\begin{tabular}{lccccccc}
\hline Hypothesis & & $\mathrm{N}$ & Observed $\mathrm{P}$ & $\mathrm{P}$ & \multicolumn{2}{l}{ Sig. } & \\
\hline The level of meaningful sense is higher & $\mathrm{H}_{0}$ & $\mathrm{~N} \leq 50 \%$ & 4 & 0.04 & 0.5 & 0.000 & Confirmed \\
& $\mathrm{H}_{1}$ & $\mathrm{~N}>50 \%$ & 108 & 0.96 & 0.5 & 0.000 & \\
The level of feelings of competence is higher & $\mathrm{H}_{0}$ & $\mathrm{~N} \leq 50 \%$ & 0 & 0.00 & 0.5 & 0.000 & Confirmed \\
& $\mathrm{H}_{1}$ & $\mathrm{~N}>50 \%$ & 112 & 1.00 & 0.5 & 0.000 & \\
& $\mathrm{H}_{0}$ & $\mathrm{~N} \leq 50 \%$ & 4 & 0.04 & 0.5 & 0.000 & Confirmed \\
The level of feeling of self-organization & $\mathrm{H}_{1}$ & $\mathrm{~N}>50 \%$ & 108 & 0.96 & 0.5 & 0.000 & \\
higher & $\mathrm{H}_{0}$ & $\mathrm{~N} \leq 50 \%$ & 5 & 0.04 & 0.5 & 0.000 & Confirmed \\
The level of sense of efficacy is higher & $\mathrm{H}_{1}$ & $\mathrm{~N}>50 \%$ & 107 & 0.96 & 0.5 & 0.000 & \\
& & & & & & &
\end{tabular}

As we can observe from the results of Table 2, all null hypotheses have been rejected in favor of alternative hypotheses and we can conclude that training programs could increase the level of meaningful sense and the feeling of competence. In addition, the results indicate that training programs could increase employees' self-organization as well as efficacy characteritics. 


\section{Conclusion}

Having reliable and skilled employees are essential component of any organization. Employees are considered as intangible assets for most organizations and they are the primary source of making value added decisions. On the other hand, a learning organization is capable of making continous improvement and surives in today's competetive environment. Training employees plays essential role on helping firms create more value added.

In this paper, we have presented an empirical investigation to study the impact of attending some employees in some graduate studies in one of Iranian schools located in city of Tehran, Iran. The proposed study of this paper chose a sample of limited people and, through distribting a well known questionnaire, examined the effect of attending these programs on empowering employees. The results of our survey have indicated that while training programs could create meaningful sense and help them have a better sense of efficacy but it did not create any feeling of competence or established any feeling of self-organization. The survey also has concluded that training programs could increase the level of meaningful sense and the feeling of competence. In addition, the results indicate that training programs could increase employees' self-organization as well as efficacy characteritics.

The moral story is that training alone cannot contribute significantly on organizations and there is a need to allocate appropriate people in positions, which are well suited for them and organizations must follow a sense of meritocratic.

\section{Acknowledgment}

The authors would like to thank the annonymous referees for carefully reading the content of this paper and helped us present a better version of our work. We are also delighted for the cooperation of all manager who participated in our survey.

\section{References}

Abtahi, S.H., \& Saadi, M.R. (2012). A conceptual model for empowering bank's human resources: A case study of Tejarat bank of Iran. Management Science letters, 2(3), 979-988.

Amir Khani, A.H., Darvish, H., Miandari, K., \& Sotudeh Arani, H. (2013). The role of spiritual leadership on empowering employees: A case study of educational system. Management Science letters, 3(3), 1013-1018.

Conger, J. A., \& Kanungo, R. N. (1988). The empowerment process: Integrating theory and practice. Academy of management review, 13(3), 471-482.

Eylon, D. (1998). Understanding empowerment and resolving its paradox: Lessons from Mary Parker Follett. Journal of Management History (Archive),4(1), 16-28.

Hon, A. H.Y. (2011). Enhancing employee creativity in the Chinese context: The mediating role of employee self-concordance. International Journal of Hospitality Management, 30(2), 375-384

Honold, L. (1997). A review of the literature on employee empowerment. Empowerment in organizations, 5(4), 202-212.

Johnston, M. A. (2000). Delegation and organizational structure in small businesses influences of manager's attachment patterns. Group \& Organization Management, 25(1), 4-21.

Karatepe, O.M. (2013). High-performance work practices and hotel employee performance: The mediation of work engagement. International Journal of Hospitality Management, 32, 132-140

Matthews, R. A., Diaz, W. M., \& Cole, S. G. (2003). The organizational empowerment scale. Personnel Review, 32(3), 297-318.

Page, N., \& Czuba, C. E. (1999). Empowerment: What is it. Journal of extension, 37(5), 1-5.

Spreitzer, G. M. (1996). Social structural characteristics of psychological empowerment. Academy of Management Journal, 39(2), 483-504. 
Shelton, S. T. (2002). Employees, supervisors, and empowerment in the public sector: The role of employee trust.

Quinn, R. E., \& Spreitzer, G. M. (1997). The road to empowerment: Seven questions every leader should consider. Organizational Dynamics, 26(2), 37-49.

Wilkinson, A. (1998). Empowerment: theory and practice. Personnel review, 27(1), 40-56.

Yuan, C.K., \& Lee, C.Y. (2011). Exploration of a construct model linking leadership types, organization culture, employees performance and leadership performance. Procedia - Social and Behavioral Sciences, 25, 123-136 